\title{
The effect of water density variations on the tidal flushing of animal burrows
}

\author{
S.F. Heron*, P.V. Ridd \\ Marine Geophysical Laboratory, School of Mathematical and Physical Sciences, James Cook University, Townsville, \\ Queensland 4811, Australia
}

Received 2 February 2001; accepted 24 February 2003

\begin{abstract}
Animal burrows in mangrove swamps play an important role in the transport of various soluble materials, including salt. Flushing of burrows by inundating tides provides an efficient mechanism for the exchange of these materials. The density increase in the burrow, due to salt diffusion from pore water into the burrow, causes a greater resistance to the flushing. As the salinity difference between surface and burrow waters increases, the burrows no longer flush, and hydrostatic equilibrium exists between the different density waters. A flume experiment was conducted to compare burrow flushing characteristics with theoretical predictions. The results were consistent with a simple analytical theory in predicting whether burrows would flush. When equilibrium was attained, the difference between the interface depths was $10 \%$ greater than the theoretical prediction, which was within the experimental error. In addition, a comparison between a two-opening and a three-opening burrow showed that there was no benefit to the flushing capability due to additional openings. Computational fluid dynamic models were undertaken to compare with the experimental and theoretical flushing characteristics. These were also consistent with the flushing prediction theory. When equilibrium was attained, the difference between the interface depths in the model was $33 \%$ greater than the theoretical prediction. The computational study with an additional opening supported the experimental evidence that there is no advantage to the flushing. Insight into small-scale processes unable to be accurately observed could be obtained from the models, e.g. oscillations of density interfaces and turbulent scales at the burrow openings. The consistency in prediction of flushing between the theoretical, experimental and computational methods, now allows modelling of more complex burrow structures with great confidence.
\end{abstract}

(C) 2003 Elsevier Ltd. All rights reserved.

Keywords: burrows; computer simulation; flushing time

\section{Introduction}

Computational fluid dynamics (CFD) gives an insight into processes that are often otherwise unable to be observed. Many industrial processes can increase their efficiency by interpretation of CFD models. CFD packages are commonly used for these purposes, one example of such packages being the Fluid Dynamics Analysis Package (FIDAP). Similarly it is possible to use these techniques and packages to examine in detail

\footnotetext{
* Corresponding author. Department of physics, Georgetown University, Washington, DC 20057, USA

E-mail address: sfh5@georgetown.edu (S.F. Heron).
}

the flows in environmental situations which are difficult or unable to be physically observed.

CFD models of large scale processes have given greater insight into processes in oceans, bays and estuaries (Bode, Mason, \& Middleton, 1997; Furukawa, Wolanski, \& Mueller, 1997; Wolanski \& Ridd, 1986), however, modelling of small-scale environmental processes is much less common. Flow in animal burrows has, in recent years, received an increased focus (Allanson, Skinner, \& Imberger, 1992; Webster, 1992). Burrows perform a significant role in the exchange between surface and ground waters in a variety of marine and freshwater environments. Irrigation and flushing of animal burrows located in the beds and banks of lakes, rivers, estuaries and ocean coasts, provide a mechanism which can enhance water exchange, 
and thus the transport of materials such as salt, nutrients, oxygen and pollutants.

In mangrove areas, the transport of salt is of great importance. As groundwater is absorbed from the sediment by the mangrove roots, salt is excluded at the roots. There is thus an increase in salt concentration in the soil surrounding the mangrove roots. This sediment is highly impermeable and greatly impedes the diffusive transport of the salt away from the roots; the coefficient of salt diffusion for mangrove swamp sediment was calculated by Hollins, Ridd, and Read (1999) to be $4.6 \times 10^{-5} \mathrm{~m}^{-2} \mathrm{day}^{-1}$. In swamps without animal burrows the salt must diffuse from the root to the surface water, however, with burrows present the distance over which diffusion occurs is much shorter, and thus the diffusion time is significantly decreased. The removal of the burrow water then completes the salt-removal process. As a high tide inundates the swamp, the water surface has a small, but significant, slope. The pressure difference across the burrow openings due to this slope causes flow in the burrow; flushing the burrow water, and thus removing the salt. Hollins and Ridd (in press), Ridd (1996), and Stieglitz, Ridd, and Muller (2000) showed that burrow water, and hence the salt, is significantly flushed by any tide that inundates the ground surface at the burrow openings. The burrow flushing process can provide a much faster mechanism for salt-removal from root to surface, as compared with diffusion from root to surface.

Stieglitz et al. (2000) suggested that the flushing of animal burrows might be completed in approximately $1 \mathrm{~h}$, within the time span of a single-tidal event. These measurements were undertaken by replacing burrow water with a same-density sugar solution, and measuring the conductivity change as the sugar water was flushed and replaced with (higher conductivity) surface water. In contrast, Hollins and Ridd (in press) used two methods, which suggest that the volume of water flushed during a single-tidal event is approximately one-third of the burrow volume. The first of these methods used rhodamine dye to trace the burrow water during the tidal inundation, and measured the relative fluorescence over the tidal period to determine the mixing characteristics. The second involved oxygen measurements of the burrow water. Oxygen diffusion from mangrove roots and microbial oxygen consumption were accounted for, and the results showed a significant increase in oxygen concentration as oxygen-rich surface water inundated the burrow water. The two methods of Hollins and Ridd (in press) were consistent in the observation that one-third of the burrow volume was flushed during the tidal event.

Heron and Ridd (2001) described a method by which CFD can be used to predict the tidal flushing of animal burrows. The method defined a pressure gradient across the flow domain, according to the water slope, which caused flow across the surface and through the burrow.
Obstructions to the surface flow (including surface and buttress roots) were modelled and their effects on the surface water velocities and burrow flushing rates were determined. Flushing times were measured for burrows of varying complexity of geometry. Burrows in some mangrove forests have been observed to reach total depths of $1.2 \mathrm{~m}$ (Stieglitz et al., 2000), and models were created for single loop and several multiply-connected loops to this depth. The study showed that burrow flushing times predicted by CFD models were of the same order as those observed in mangrove swamps, i.e. that there is significant flushing of burrows within a single-tidal event.

This work furthers the work of Heron and Ridd (2001) by investigating the effect on flow rates of density variations in the flow domain. As discussed, mangrove roots exclude salt into the highly impermeable sediment, which then diffuses into the animal burrows. This causes the density of burrow water to increase and so it becomes greater than that of the surface 'flushing' water. A typical value for the density of the surface water (sea water) is $1028 \mathrm{~kg} \mathrm{~m}^{-3}$, and burrow water density may reach $1053 \mathrm{~kg} \mathrm{~m}^{-3}$ at the landward boundary of the swamp, however, values around $1033 \mathrm{~kg} \mathrm{~m}^{-3}$ (approximately $0.5 \%$ variation) are more common. This increase in density is expected to increase the time required to flush the burrow. Flume experiments using a simple burrow geometry are compared with the CFD model output. This work also incorporates the observation that burrows often have more than the simple two openings, and investigates this effect upon the flushing rate of the burrow.

\section{Methods}

\subsection{Experiment}

A flume tank was constructed of the design shown in Fig. 1a. The flume was constructed from PVC pipe, and clear plastic tubing was used for the burrow. The diameter of the flume was $D_{\mathrm{p}}=15 \mathrm{~cm}$, and the lengths upstream and downstream of the burrow were $l_{\mathrm{u}}=4.0 \mathrm{~m}$ and $l_{\mathrm{d}}=1.7 \mathrm{~m}$, respectively. The characteristic lengths of the burrow were the internal diameter, $w=3 \mathrm{~cm}$, the distance between the openings, $l=40 \mathrm{~cm}$, and the depth to the inside of the burrow, $d=23 \mathrm{~cm}$. These values were selected to be consistent with observations of the burrows of the crab, Sesarma messa, in mangrove swamps, and with burrows from literature (Allanson et al., 1992; Stieglitz et al., 2000).

Surface water from the inflow reservoir was pumped into a flow regulator and then through the flume to the outflow reservoir, returning to the inflow reservoir. Large variations in burrow and flume temperatures were observed over short time periods. These were caused by 
(a)
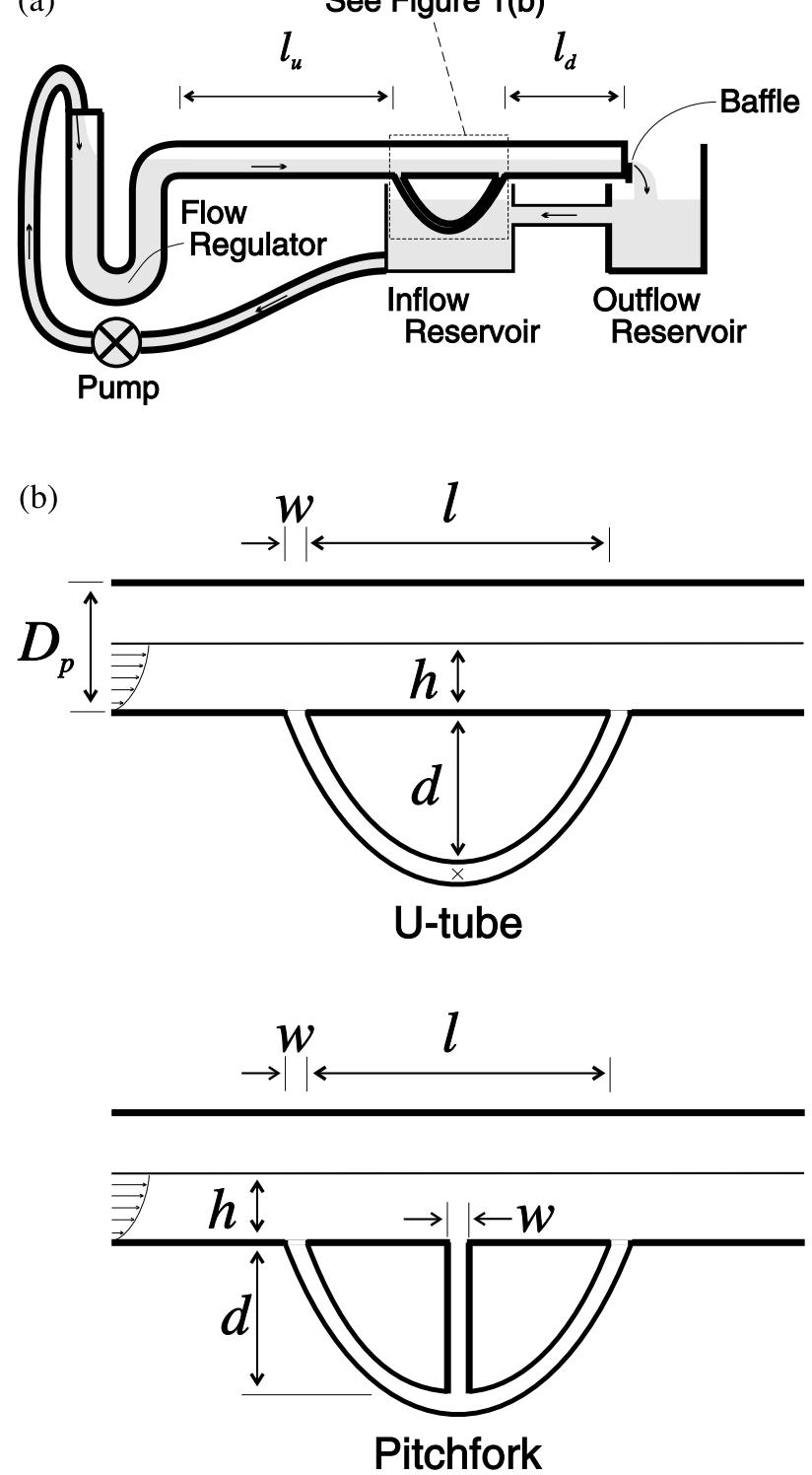

Fig. 1. (a) Schematic diagram of the flume tank design. (b) Enlarged diagram of the U-tube and pitchfork burrows used in the flume tank experiment. The bottom mid-point of the U-tube, marked $\times$, is discussed in Section 3.3.

direct sunlight on the transparent burrow and the effect of atmospheric temperature variations. The temperature difference between super- and sub-terranean waters in actual burrows will impact the flushing times and conditions. This is because the density of water varies with temperature. However, to determine if burrows could be flushed by the surface water pressure gradient, these temperature variations were minimised. To achieve this, the burrow was submerged in the inflow reservoir. The purpose of the flow regulator is to remove any inconsistencies in the flow from the pumping process. The flume length upstream of the burrow was sufficient to allow the vertical velocity profile to fully develop. A baffle was placed across the reservoir end of the pipe and adjusted to maintain constant water depth, $h=7.5 \mathrm{~cm}$, for varying water slopes (i.e. along-flume pressure gradients). Surface water velocities were selected in the approximate range of $10-20 \mathrm{~cm} \mathrm{~s}^{-1}$.

For simplicity of the experiment, fresh water (density $\rho_{1}=1000 \mathrm{~kg} \mathrm{~m}^{-3}$ ) was used as the surface water. The burrow flushing properties were measured by filling the burrow with salt water (density range $\rho_{2}=1001$ $-1005 \mathrm{~kg} \mathrm{~m}^{-3}$; i.e. $0.1-0.5 \%$ variation from the surface water). These values are sufficient for the comparison with natural situations as it is the relative difference in densities between the surface and burrow waters which is important.

The experimental work was undertaken for a simple Utube burrow and repeated for a three-opening 'pitchfork' burrow (see Fig. 1b). A single burrow structure inhabited by Sesarma messa observed by Stieglitz et al. (2000) had nine surface openings in a cross-sectional area of $0.64 \mathrm{~m}^{2}$. This suggests that adjacent multiple burrow openings may be separated by a distance of approximately 15$25 \mathrm{~cm}$, with greatest separation of openings in the range $40-70 \mathrm{~cm}$. The pitchfork burrow was investigated to determine if the additional surface opening had an influence on the flushing rate.

Water slopes were measured during a tidal inundation in a mangrove swamp, and are shown in Fig. 2. The slopes were measured during a single spring high tide event of $3.41 \mathrm{~m}$ in 1948 on 25 October 2000 in Townsville, Australia. This event was selected as it was in the middle of a spring tide series and was, therefore, among the highest inundations. Two wooden posts, with measuring tapes attached, were hammered into the ground a distance of $23.42 \mathrm{~m}$ apart. The depth of the tidal water was regularly measured at these locations throughout the inundation. The depth measurements were reconciled to each other when the tidal water was stationary. The

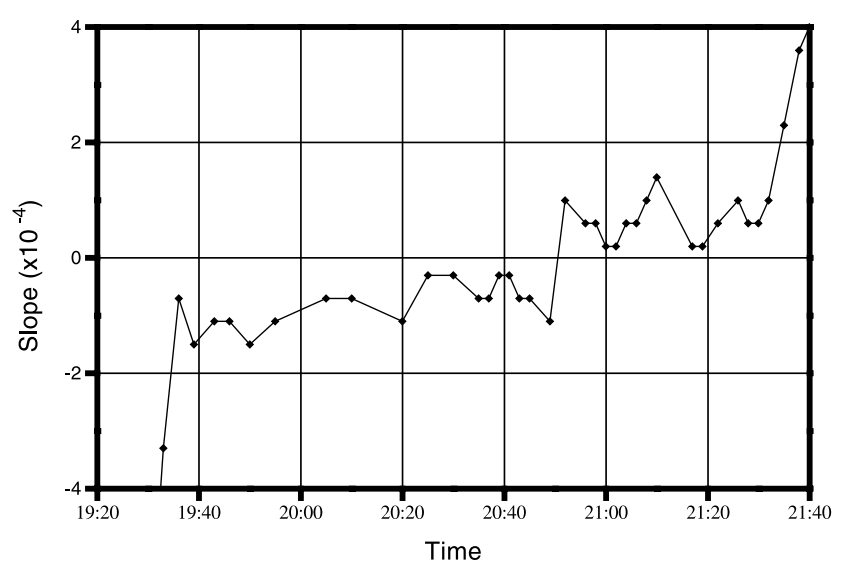

Fig. 2. Surface water slopes in mangrove swamp measured during spring high tide event of $3.41 \mathrm{~m}$ in 1948,25 October 2000 . The mangrove swamp was located adjacent to Gordon's Creek, Townsville. The time lag of the inundation is due to the slightly inland location of the swamp. 
measured slopes were predominantly $1 \times 10^{-4}$ on both flood and ebb tides with slopes as high as $1 \times 10^{-3}$ and $4 \times 10^{-4}$ observed in the initial and final stages, respectively, of the tide. This range of values is consistent with reported values (Aucan \& Ridd, 1999; Wolanski, Mazda, \& Ridd, 1992).

The water slope in the flume tank could be determined whenever the burrow was filled with a dyed salt solution with density sufficiently high that the burrow would not flush. The different density waters $\left(\rho_{1}<\rho_{2}\right)$ will reach hydrostatic equilibrium as shown in Fig. 3. The positions of the interfaces between the surface and burrow waters can be measured. The pressure in each side of the U-tube will be equal, i.e.:

$\rho_{1} g h_{1}+\rho_{1} g d_{1}=\rho_{1} g h_{2}+\rho_{1} g d_{2}+\rho_{2} g\left(d_{1}-d_{2}\right)$

and thus,

$\left(h_{1}-h_{2}\right)=\left(\frac{\rho_{2}-\rho_{1}}{\rho_{1}}\right)\left(d_{1}-d_{2}\right)$

The surface water slope is given by $S_{0}=\left(h_{1}-h_{2}\right) / l$, so the difference in the interface depths is:

$\Delta d=\left(d_{1}-d_{2}\right)=\frac{\rho_{1} S_{0} l}{\Delta \rho}$

where $\rho_{1}$ is the surface water density, $l$ the distance between the burrow openings and $\Delta \rho$ is the difference in surface and burrow densities.

The maximum slope obtained with the smooth PVC pipe was $3 \times 10^{-4}$. The Manning coefficient for smooth PVC pipe is reported as $n=0.009$ (Street, Watters, \& Vennard, 1996), and is related to the flow velocity, $V$, by:

$V=\frac{1}{n} R^{2 / 3} S_{0}^{1 / 2}$

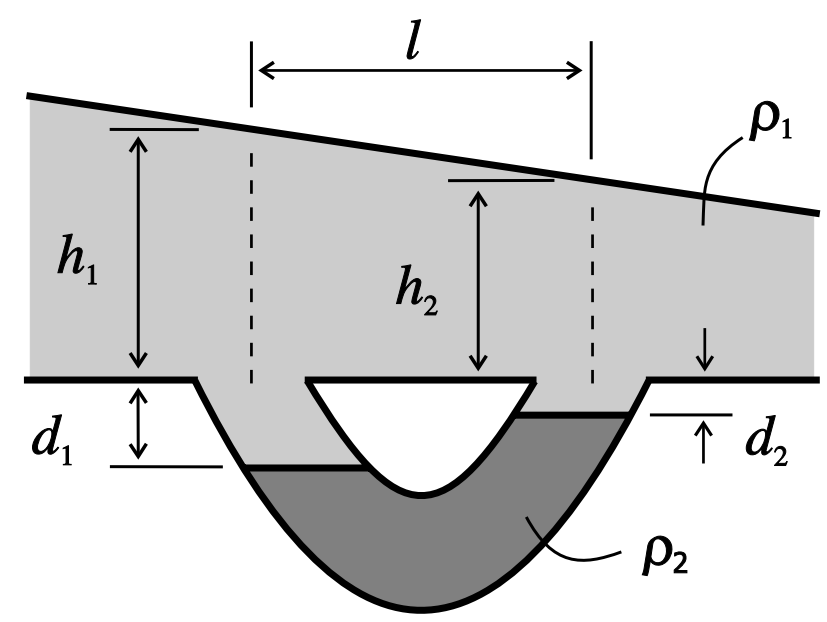

Fig. 3. Hydrostatic pressure equilibrium in a U-tube burrow due to surface water slope and different density burrow and surface waters. where $R$ is the hydraulic radius (ratio of water crosssectional area to wetted perimeter). If we keep the flow velocity and the hydraulic radius constant in the experimental setup, the roughness (corresponding to $n$ ) must be increased to produce the desired slope range. Sand and gravel were applied to the PVC surface to increase the roughness characteristic, and thereby the maximum slope.

\subsection{Numerical model}

The model geometry matched the along flow crosssection of the flume tank (see Fig. 1b) and the model domain length was defined as $2.0 \mathrm{~m}$, with the burrow located centrally. The tidal flushing was modelled in two dimensions using FIDAP. This package uses the finite element method to solve the isothermal Navier-Stokes equations (Fluid Dynamics International, 1993):

$$
\begin{array}{ll}
\text { Continuity: } & \frac{\partial \rho}{\partial t}+\nabla \cdot \rho \mathbf{u}=0 \\
\text { Momentum: } & \rho\left(\frac{\partial \mathbf{u}}{\partial t}+\mathbf{u} \cdot \nabla \mathbf{u}\right) \\
& =-\nabla p+\nabla \cdot \tau-\rho \mathbf{g}+\rho \mathbf{f}
\end{array}
$$

Transient + Convective $=$ Pressure + Viscous

$$
- \text { Buoyancy }+ \text { Body Force }
$$

where the symbolism is as follows - $\rho$ is the density; $\mathbf{u}$ the velocity; $\nabla$ the gradient, divergence operator; $p$ the pressure; $\tau$ the stress tensor; $g$ the gravity; $t$ the time and $\mathbf{f}$ is the body force.

All parameters and equations were non-dimensionalised to provide greater ease and flexibility in the implementation of the models.

The boundary condition driving the surface water flow was determined from the surface slope of the incoming tidal water. The pressure difference across the domain due to this slope was simulated and produced the appropriate vertical velocity profile. Heron and Ridd (2001) outlines this method further.

The effects of turbulence were modelled using the mixing length model. This model is automated within the framework of FIDAP version 7.62 and defines the appropriate mixing length for each individual mesh element. This boundary layer model allows for the transition from the viscous sub-layer to the outer flow region. This simplifies the solution process as there is no requirement for additional turbulence parameters, and therefore there are less equations to solve.

The steady-state velocity and pressure profiles were determined by solving the time-independent continuity and momentum equations, with constant density assumed throughout the domain. These profiles were used 
as initial conditions for the transient density-dependent models.

The variation in density between surface and burrow water is small compared with the overall magnitude of density, and so it is appropriate to use the Boussinesq approximation. This approximation assumes that the density is constant in all terms of the momentum equation except the Buoyancy term. The effect of density variation for this term was modelled by use of a tracer to define the more saline water. Density is defined for the Buoyancy term by:

$\rho=\rho_{1}\left(1-\beta_{\mathrm{c}} c\right)$

where $c$ is the concentration of tracer and $\beta_{\mathrm{c}}$ is the tracer volume expansion coefficient.

The time-dependent tracer equation is defined for tracer $n$, and must be solved in conjunction with the continuity and momentum equations:

Tracer, $n: \quad \rho\left(\frac{\partial c_{n}}{\partial t}+u \cdot \nabla c_{n}\right)=\rho \nabla \cdot\left(\alpha_{n} \nabla c_{n}\right)+q_{c_{n}}+R_{n}$

Transient + Convective $=$ Diffusive + Source + Reaction

where $c_{n}$ is the tracer concentration, $\alpha_{n}$ the molecular diffusivity, $q_{c_{n}}$ the source term and $R_{n}$ is the chemical reaction rate.

The molecular diffusivity of the tracer was defined as the value of salt in water at $25^{\circ} \mathrm{C}, \alpha_{n}=1.6 \times 10^{-9} \mathrm{~m}^{2} \mathrm{~s}^{-1}$ (Nye \& Tinker, 1977). For this analysis the source and reaction terms are removed, however, these could be retained for further analyses, e.g. investigating oxygen transport.

The initial condition for the tracer is defined as being unity for the burrow water, and zero for the surface water. The tracer volume expansion coefficient, $\beta_{\mathrm{c}}$, is defined by the densities of surface $\left(\rho_{1}\right)$ and burrow $\left(\rho_{2}\right)$ waters, as:

$\beta_{\mathrm{c}}=\left(\frac{\rho_{1}-\rho_{2}}{\rho_{1}}\right)$

For example, taking the values of $\rho_{1}=1000 \mathrm{~kg} \mathrm{~m}^{-3}$ and $\rho_{2}=1005 \mathrm{~kg} \mathrm{~m}^{-3}$, the value for the volume expansion coefficient is $\beta_{\mathrm{c}}=-0.005$.

Models with the U-tube and pitchfork geometries were solved to compare with the experimental work.

\section{Results}

\subsection{Flume experiment}

The experiment was conducted for burrow water salt concentrations of 1,3 and $5 \mathrm{gl}^{-1}$, and with four different velocities at the top of the surface water. The flushing characteristics were determined for each of the U-tube and pitchfork burrows. The results are illustrated in Table 1a and $\mathrm{b}$, respectively. The $\Delta d$ values for the pitchfork burrow are determined from the right- and left-hand tines, i.e. the ' $U$ ' sections of the burrow. The interface in the middle (vertical) tine of the pitchfork was always between the depths of the outer sections at equilibrium. The experimental error in the $\Delta d$ values is $0.5 \mathrm{~cm}$.

There are three distinct regions of each table: (1) those for which flushing occurs quickly (dark grey), (2) those for which equilibrium was reached (light grey) and (3) those which lie on the boundary between these conditions (white), i.e. partial or very slow flushing. In this third region, the interface positions were initially very close to equilibrium and diffusion of salt across the interfaces eventually started the flushing of the burrow. The asterisk $\left(^{*}\right)$ indicates when complete flushing has eventually occurred under these conditions.

Table 1

Experimental flushing characteristics for U-tube and pitchfork burrows

\begin{tabular}{llll}
\hline & \multicolumn{1}{l}{ Burrow water salt concentration $\left(\mathrm{g} \mathrm{l}^{-1}\right)$} & \\
\cline { 2 - 4 } Surface water velocity $\left(\mathrm{cm} \mathrm{s}^{-1}\right)$ [slope] & 1 & 3 & 5 \\
\hline (a) Experimental flushing characteristics for & U-tube burrow & \\
$10.4[1.64]$ & Equilibrium $\Delta d=9.0 \mathrm{~cm}$ & Equilibrium $\Delta d=2.2 \mathrm{~cm}$ & Equilibrium $\Delta d=1.6 \mathrm{~cm}$ \\
$13.4[2.72]$ & Equilibrium $\Delta d=14.5 \mathrm{~cm}$ & Equilibrium $\Delta d=4.0 \mathrm{~cm}$ & Equilibrium $\Delta d=2.5 \mathrm{~cm}$ \\
$16.8[4.27]$ & *Flushed in $15 \min 30 \mathrm{~s}$ & Equilibrium $\Delta d=4.5 \mathrm{~cm}$ & Equilibrium $\Delta d=3.5 \mathrm{~cm}$ \\
$20.9[6.61]$ & Flushed in $2 \min 20 \mathrm{~s}$ & Equilibrium $\Delta d=9.5 \mathrm{~cm}$ & Equilibrium $\Delta d=5.5 \mathrm{~cm}$ \\
(b) Experimental flushing characteristics for pitchfork burrow & & \\
$10.4[1.64]$ & Equilibrium $\Delta d=6.0 \mathrm{~cm}$ & Equilibrium $\Delta d=2.25 \mathrm{~cm}$ & Equilibrium $\Delta d=1.25 \mathrm{~cm}$ \\
$13.4[2.72]$ & Equilibrium $\Delta d=14.25 \mathrm{~cm}$ & Equilibrium $\Delta d=2.75 \mathrm{~cm}$ & Equilibrium $\Delta d=2.5 \mathrm{~cm}$ \\
$16.8[4.27]$ & $*$ Flushed in 20 min $08 \mathrm{~s}$ & Equilibrium $\Delta d=7.5 \mathrm{~cm}$ & Equilibrium $\Delta d=3.0 \mathrm{~cm}$ \\
$20.9[6.61]$ & Flushed in 3 min $15 \mathrm{~s}$ & Equilibrium $\Delta d=11.0 \mathrm{~cm}$ & Equilibrium $\Delta d=4.75 \mathrm{~cm}$ \\
\hline
\end{tabular}

Direct flushing — dark grey, equilibrium — light grey, boundary condition — white. The asterisk $\left({ }^{*}\right)$ indicates when complete flushing has eventually occurred under these conditions. 
To determine the slopes corresponding to each velocity one can eliminate $S_{0}$ from Eqs. (1) and (2), which leads to the expression:

$\sqrt{\Delta \rho \Delta d}=\left\{\sqrt{\rho_{1} L} \frac{n}{R^{2 / 3}}\right\} v$

Fig. 4 shows the linear relation between $\sqrt{\Delta \rho \Delta d}$ and $v$ for the flume data. The linear regression through the origin has a slope of 2.55 (with standard deviation of 0.18 ). As the surface water density and the opening separation are known, one can determine the proportionality term $(1 / n) R^{2 / 3}$ in Eq. (2) from this slope. The relation between the surface slope, $S_{0}$, and surface velocity, $v$, for the flume is thus known. The slopes corresponding to the velocities are bracketed next to the velocities in Table 1. The error in the calculation of the slopes is $13 \%$.

We are now able to compare the measured $\Delta d$ with those calculated using Eq. (1), as shown in Fig. 5. There is a variation of $10 \%$ between the experimental values and the predicted values, which is within the experimental error.

\subsection{CFD: simple $U$-tube burrow with density variation}

The initial density-dependent CFD study was conducted using the simple U-tube burrow with the same characteristic dimensions as for the flume experiment. Values for the tracer volume expansion coefficient were defined to correspond with density differences between surface and burrow water in the range $1-5 \mathrm{~kg} \mathrm{~m}^{-3}$. Slope values were input to the model in the range $1 \times 10^{-4}$ $1 \times 10^{-3}$. Results of the models are shown in Table $2 \mathrm{a}$.

Comparison of the flume tank results with those from the model shows that the distinction between the three regions (direct flushing, boundary region and equilibrium) is consistent with the $S_{0}$ and $\Delta \rho$ values.

Plotting the interface depth difference, $\Delta d$, at equilibrium for the model against theoretical prediction (Fig. 6)

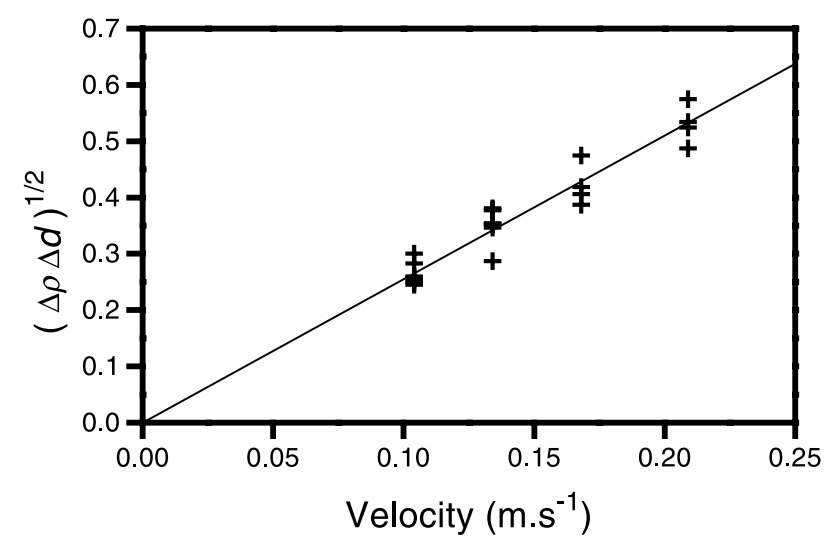

Fig. 4. Scatter plot of $\sqrt{\Delta \rho \Delta d}$ vs $v$ from experimental data. The straight line slope is 2.55 .

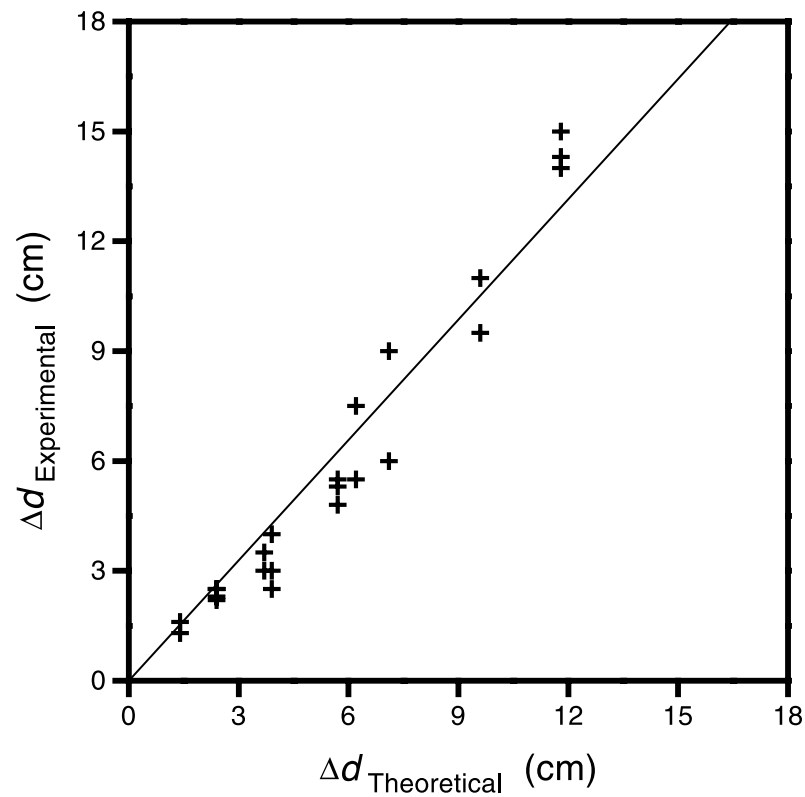

Fig. 5. Interface depth difference, $\Delta d$, at equilibrium. Experimental values plotted against theoretical values. The straight line slope is 1.10.

shows that the model over-predicts the theory by $33 \%$, compared with $10 \%$ for the flume tank. This difference is most likely due to the different turbulent roughness parameters in the flume and model (automated definition). However, this is a secondary effect compared with the pressure difference due to the slope, which is the primary influence upon the flushing properties of the burrows. While this difference is significant, the consistency between the model and experiment in predicting whether a burrow will flush remains. Future work will attempt to overcome this variation using a different method for turbulence definition.

The CFD models were also run for the pitchfork burrow geometry, and the results are summarised in Table $2 \mathrm{~b}$. Density differences of 1,2 and $3 \mathrm{~kg} \mathrm{~m}^{-3}$ were modelled to compare flushing rates with those of the U-tube geometry. The higher density differences were not re-modelled as they were expected to reach equilibrium for all slope values, as for the U-tube burrow.

If these results are compared with those of the U-tube (Table 2a), the consistency in the distinction between the three regions can again be seen. The pitchfork flushing times are slightly greater in general, in comparison with the U-tube, which is probably reflective simply of the increase in volume of the burrow. The interface depth difference, $\Delta d$, is also slightly greater for the pitchfork than for the U-tube. This may be attributed to the increase in friction in the burrow region, due to the additional opening; hence an increase in the localised slope, and thus the $\Delta d$ value. From comparison of the results for the different geometries of experimental and computational approaches, it is clear that there is no 


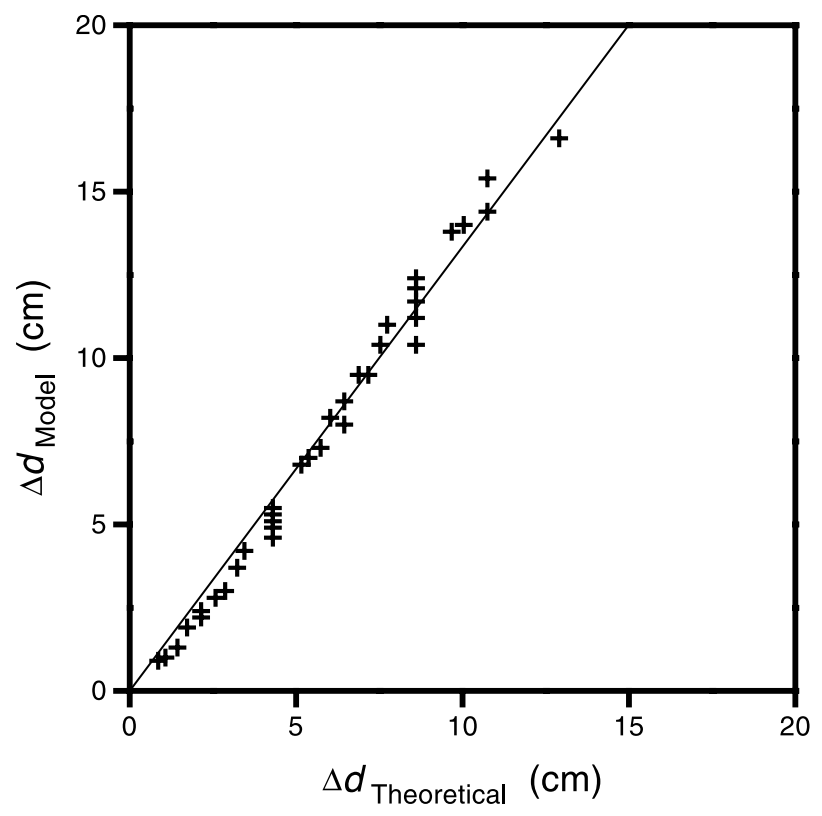

Fig. 6. Interface depth difference, $\Delta d$, at equilibrium. CFD model values plotted against theoretical values. The straight line slope is 1.33 .

advantage to the flushing in having the additional surface opening.

\subsection{CFD: small-scale processes}

From the models insight can be gained into smallscale processes that cannot be accurately observed. For situations where equilibrium is reached, the model shows the surface water plume moving down the upstream opening of the burrow towards the equilibrium point. The inertia of the flushing motion causes the pressure equilibrium to be passed. This causes the burrow flow to reverse until the equilibrium is again overshot, but to a lesser extent, and the burrow water flow is again in the forward direction. This oscillatory motion continues until the equilibrium is attained.

This damped oscillation effect in animal burrows was described in Ridd (1996) and used to determine the friction to the flow of the burrow walls. Ridd (1996) perturbed a filled burrow and then considered the position of the interface between water and air which followed the damped oscillation equation:

$x=\mathrm{e}^{-t / \tau}(A \cos \omega t+B \sin \omega t)$

where $x$ is the interface position about the equilibrium position, $t$ the time, $\tau$ the characteristic decay time of the oscillation and $\omega$ is the angular frequency of the oscillation. $A$ and $B$ are arbitrary constants.

A similar effect is observed in the density-dependent flushing, with damped oscillations of the burrowsurface water interface. Fig. 7 shows the along-burrow flow determined by the model at the bottom mid-point of the burrow (marked in Fig. 1b with $\times$ ). The data shown are for slope and density difference of $3 \times 10^{-4}$ and $4 \mathrm{~g}^{-1}$, respectively. Here the oscillation of the flow direction can easily be observed, as can the exponential decay of the magnitude of flow. The period of oscillation

Table 2

Flushing characteristics for U-tube and pitchfork burrows from the CFD model

\begin{tabular}{|c|c|c|c|c|c|}
\hline \multirow[b]{2}{*}{$S_{0}\left(\times 10^{-4}\right)$} & \multicolumn{5}{|l|}{$\Delta \rho\left(\mathrm{kg} \mathrm{m}^{-3}\right)$} \\
\hline & & 2 & 3 & 4 & 5 \\
\hline \multicolumn{6}{|c|}{ (a) Flushing characteristics for U-tube burrow from the CFD model } \\
\hline 1 & Equilibrium $\Delta d=4.6 \mathrm{~cm}$ & Equilibrium $\Delta d=2.2 \mathrm{~cm}$ & Equilibrium $\Delta d=1.3 \mathrm{~cm}$ & Equilibrium $\Delta d=1.0 \mathrm{~cm}$ & Equilibrium $\Delta d=0.9 \mathrm{~cm}$ \\
\hline 2 & Equilibrium $\Delta d=10.4 \mathrm{~cm}$ & Equilibrium $\Delta d=4.9 \mathrm{~cm}$ & Equilibrium $\Delta d=3.0 \mathrm{~cm}$ & Equilibrium $\Delta d=2.4 \mathrm{~cm}$ & Equilibrium $\Delta d=1.9 \mathrm{~cm}$ \\
\hline 3 & Equilibrium $\Delta d=16.6 \mathrm{~cm}$ & Equilibrium $\Delta d=8.0 \mathrm{~cm}$ & Equilibrium $\Delta d=5.1 \mathrm{~cm}$ & Equilibrium $\Delta d=3.7 \mathrm{~cm}$ & Equilibrium $\Delta d=2.8 \mathrm{~cm}$ \\
\hline 4 & *Flushed in $203 \mathrm{~s}$ & Equilibrium $\Delta d=11.2 \mathrm{~cm}$ & Equilibrium $\Delta d=7.3 \mathrm{~cm}$ & Equilibrium $\Delta d=5.3 \mathrm{~cm}$ & Equilibrium $\Delta d=4.2 \mathrm{~cm}$ \\
\hline 5 & *Flushed in $118 \mathrm{~s}$ & Equilibrium $\Delta d=14.4 \mathrm{~cm}$ & Equilibrium $\Delta d=9.5 \mathrm{~cm}$ & Equilibrium $\Delta d=7.0 \mathrm{~cm}$ & Equilibrium $\Delta d=5.5 \mathrm{~cm}$ \\
\hline 6 & Flushed in $90 \mathrm{~s}$ & $20 \%$ Flushed in $355 \mathrm{~s}$ & Equilibrium $\Delta d=11.7 \mathrm{~cm}$ & Equilibrium $\Delta d=8.7 \mathrm{~cm}$ & Equilibrium $\Delta d=6.8 \mathrm{~cm}$ \\
\hline 7 & Flushed in $78 \mathrm{~s}$ & $*$ Flushed in $182 \mathrm{~s}$ & Equilibrium $\Delta d=14.0 \mathrm{~cm}$ & Equilibrium $\Delta d=10.4 \mathrm{~cm}$ & Equilibrium $\Delta d=8.2 \mathrm{~cm}$ \\
\hline 8 & Flushed in $74 \mathrm{~s}$ & Flushed in $118 \mathrm{~s}$ & $5 \%$ Flushed $315 \mathrm{~s}$ & Equilibrium $\Delta d=12.1 \mathrm{~cm}$ & Equilibrium $\Delta d=9.5 \mathrm{~cm}$ \\
\hline 9 & Flushed in $60 \mathrm{~s}$ & Flushed in $91 \mathrm{~s}$ & $*$ Flushed in $255 \mathrm{~s}$ & Equilibrium $\Delta d=13.8 \mathrm{~cm}$ & Equilibrium $\Delta d=11.0 \mathrm{~cm}$ \\
\hline 10 & Flushed in $55 \mathrm{~s}$ & Flushed in $76 \mathrm{~s}$ & *Flushed in $154 \mathrm{~s}$ & Equilibrium $\Delta d=15.4 \mathrm{~cm}$ & Equilibrium $\Delta d=12.4 \mathrm{~cm}$ \\
\hline
\end{tabular}

(b) Flushing characteristics for pitchfork burrow from the CFD model

$\begin{array}{rlll}1 & \text { Equilibrium } \Delta d=4.8 \mathrm{~cm} & \text { Equilibrium } \Delta d=2.2 \mathrm{~cm} & \text { Equilibrium } \Delta d=1.4 \mathrm{~cm} \\ 2 & \text { Equilibrium } \Delta d=10.6 \mathrm{~cm} & \text { Equilibrium } \Delta d=5.1 \mathrm{~cm} & \text { Equilibrium } \Delta d=3.3 \mathrm{~cm} \\ 3 & \text { Equilibrium } \Delta d=16.9 \mathrm{~cm} & \text { Equilibrium } \Delta d=8.3 \mathrm{~cm} & \text { Equilibrium } \Delta d=5.4 \mathrm{~cm} \\ 4 & \text { *Flushed in } 213 \mathrm{~s} & \text { Equilibrium } \Delta d=11.4 \mathrm{~cm} & \text { Equilibrium } \Delta d=7.6 \mathrm{~cm} \\ 5 & \text { *Flushed in } 128 \mathrm{~s} & \text { Equilibrium } \Delta d=14.8 \mathrm{~cm} & \text { Equilibrium } \Delta d=9.8 \mathrm{~cm} \\ 6 & \text { Flushed in } 99 \mathrm{~s} & \text { Equilibrium } \Delta d=18.4 \mathrm{~cm} & \text { Equilibrium } \Delta d=12.0 \mathrm{~cm} \\ 7 & \text { Flushed in } 84 \mathrm{~s} & \text { *Flushed in } 233 \mathrm{~s} & \text { Equilibrium } \Delta d=14.5 \mathrm{~cm} \\ 8 & \text { Flushed in } 74 \mathrm{~s} & \text { Flushed in } 165 \mathrm{~s} & \text { Equilibrium } \Delta d=16.8 \mathrm{~cm} \\ 9 & \text { Flushed in } 67 \mathrm{~s} & \text { Flushed in } 137 \mathrm{~s} & \text { *Flushed in } 263 \mathrm{~s} \\ 10 & \text { Flushed in } 62 \mathrm{~s} & \text { Flushed in } 120 \mathrm{~s} & \text { *Flushed in } 156 \mathrm{~s}\end{array}$

Direct flushing — dark grey, equilibrium — light grey, boundary condition — white. The asterisk $(*)$ indicates when complete flushing has eventually occurred under these conditions. 


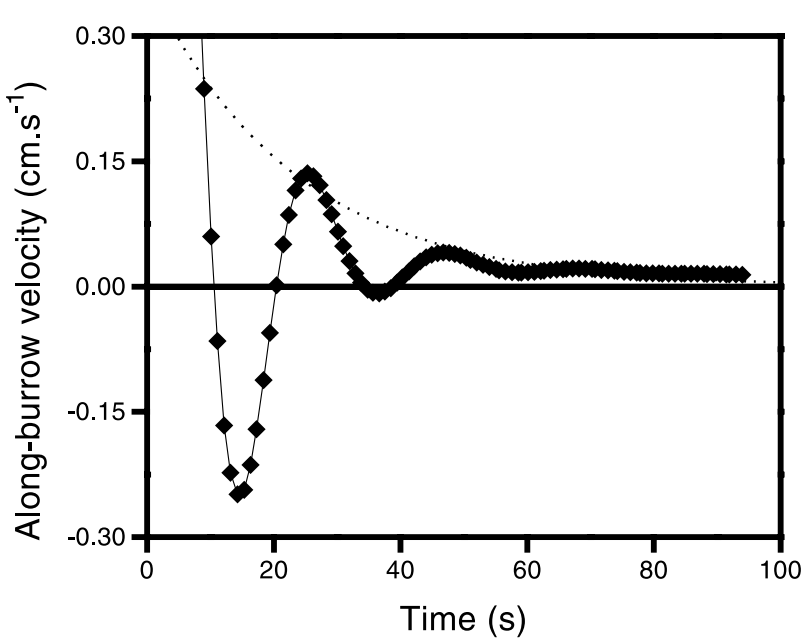

Fig. 7. Time series of the along-burrow velocity component at the bottom of the burrow, showing the damped oscillation as the system approaches hydrostatic equilibrium. The dotted line is the exponential decay fitted to the positive oscillation peaks.

is observed to be $21 \mathrm{~s}$, which corresponds to an angular frequency of $\omega=0.29 \mathrm{~s}^{-1}$. The decay time of the damped oscillation, i.e. the time to decay the oscillation amplitude by a factor of $1 / e(0.37)$, is seen to be $23 \mathrm{~s}$. As time proceeds the model shows that the system moves towards a state of equilibrium. The period and decay time observed by Ridd (1996) were of the order of 2 and $3 \mathrm{~s}$, respectively. The variation from these values is due to the large differences in the burrow length and diameter.

The effect of turbulence at the burrow openings increases the depth of both interfaces, and thus the depth to which a burrow may flush. The turbulent effect causes a rapid flushing of the burrow water at each opening, to a depth that is characteristic of the burrow. The average depth of the interfaces, $\bar{d}$, is plotted against the difference between the interface depths, $\Delta d$, in Fig. 8. The straight line relation has the equation (units in $\mathrm{cm}$ ),

$\bar{d}=0.49 \Delta d+4.0$

If the turbulent effect was ignored, the average depth would be one-half of the interface separation distance. As expected, the gradient value in Eq. (9) remains consistent with this when the turbulent effect is included. The intercept value of $d_{\text {turb }}=4 \mathrm{~cm}$ indicates the added depth due to the effect of turbulence at the burrow opening. As this value is consistent over the range of slopes and density differences, the turbulence depth will likely be dependent upon the diameter of the burrow. The linearity should be consistent for each individual burrow dimension.

The experimental and modelling results may be put together to predict the flushing of a burrow. Modifying Eq. (1) to include the scaling term determined from the flume experiment, $k=1.1$, and combining it with the

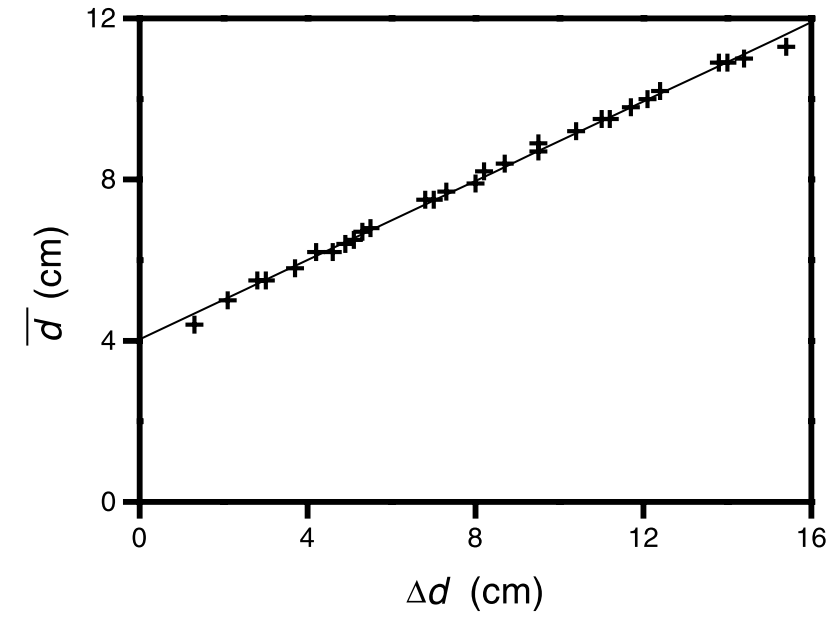

Fig. 8. Average interface depth, $\bar{d}$, plotted against the difference between interface depths, $\Delta d$, as determined by the CFD models.

turbulent effect at the opening, the final equilibrium depth of the upstream interface ( $d_{1}$ in Fig. 3 ) is given by:

$d_{1}=k \frac{\rho_{1} S_{0} L}{\Delta \rho}+d_{\mathrm{turb}}$

If the tidal and burrow characteristics cause this value to be greater than the depth of the burrow, then the burrow will directly flush.

\section{Discussion}

This study has examined the effect of water density variations on the tidal flushing of animal burrows. Higher burrow water density, as compared with that of the surface water, has been shown to limit, or indeed halt, the flushing of the burrows. This study has assumed that the burrows are empty, i.e. any effect of the inhabiting animals has been neglected. The burrow residents may inhibit the flushing by increasing the friction to the flow. However, the animals may also assist the water motion by actively irrigating their burrows. The combination of hydrostatic and biological flushing mechanisms would be a valuable study.

Eq. (10) gives a prediction for the depth to which burrows will flush by the hydrostatic flushing mechanism. Considering the tidal cycle, one may determine the salinity increase during the neap period and thus suggest the depth to which burrows can exist to guarantee flushing during spring tides. This may lead to an explanation of the position of the boundary between mangrove swamps and super-saline salt flats in relation to individual swamps. While this work has been undertaken using a simple geometry, the overall concepts are the same for the more complex, multi-loop geometries of greater-depth burrows. The consistency of these models with both experimental and theoretical predictions 
provides confidence in the results of future models with more complex burrow structures. Using these techniques, computer simulations assist our understanding of the flushing process.

\section{Acknowledgements}

Thanks to Suzanne Hollins, Mal Heron and Ian Webster for their assistance in the preparation of the manuscript. The manuscript was revised while S.F.H. was visiting Penn State Altoona.

\section{References}

Allanson, B. R., Skinner, D., \& Imberger, J. (1992). Flow in prawn burrows. Estuarine, Coastal and Shelf Science 35, 253-266.

Aucan, J., \& Ridd, P. V. (1999). Tidal asymmetry in creeks surrounded by salt flats and mangroves with small swamp slopes. Mangroves and Salt Marshes 69, 1-10.

Bode, L., Mason, L. B., \& Middleton, J. H. (1997). Reef parameterisation schemes with applications to tidal modelling. Progress in Oceanography 40, 285-324.

Fluid Dynamics International. (1993). Fluid dynamics analysis package v7.0 theory manual. Evanston, IL: FDI.
Furukawa, K., Wolanski, E., \& Mueller, H. (1997). Currents and sediment transport in mangrove forests. Estuarine, Coastal and Shelf Science 44, 301-310.

Heron, S., \& Ridd, P. V. (2001). The use of computational fluid dynamics in predicting the flushing of animal burrows. Estuarine, Coastal and Shelf Science 52, 411-421.

Hollins, S., \& Ridd, P. The concentration and consumption of oxygen in large animal burrows in tropical mangrove swamps. Estuarine, Coastal and Shelf Science, in press.

Hollins, S., Ridd, P. V., \& Read, W. W. (1999). Measurement of the diffusion coefficient for salt in salt flat and mangrove soils. Mangroves and Salt Marshes 73, 1-6.

Nye, P. H., \& Tinker, B. (1977). Solute movement in the soil-root system (pp. 69-91). Oxford: Blackwell.

Ridd, P. V. (1996). Flow through animal burrows in mangrove creeks. Estuarine, Coastal and Shelf Science 43, 617-625.

Stieglitz, T., Ridd, P., \& Muller, P. (2000). Passive irrigation and functional morphology of crustacean burrows in a tropical mangrove swamp. Hydrobiologia 421, 69-76.

Street, R. L., Watters, G. Z., \& Vennard, J. K. (1996). Elementary fluid mechanics (7th ed., 757 pp.). New York, NY: Wiley.

Webster, I. T. (1992). Wave enhancement of solute exchange within empty burrows. Limnology and Oceanography 37, 630-643.

Wolanski, E., Mazda, Y., \& Ridd, P. (1992). Mangrove hydrodynamics. In A. Robertson, \& D. Alongi (Eds.), Tropical mangrove ecosystems (pp. 43-61). Washington, DC: AGU.

Wolanski, E., \& Ridd, P. (1986). Tidal mixing and trapping in mangrove swamps. Estuarine, Coastal and Shelf Science 23, 759-771. 